\title{
More papers, more issues
}

Since it was founded in 1963, Rhinology has consisted of 4 issues per year / volume. However, we are now finding that this is not enough to accommodate the increasing number of high-quality papers we accept for publication. We do of course offer fast online publication, usually within two weeks of acceptance, but authors can wait some time for their paper to be published in a physical issue.

With the launch of our Open Access journal Rhinology Online in 2018, we have been able to offer authors an alternative route to publication, and this has been very successful with over 30 papers published to date. We expect Rhinology Online to be accepted for PubMed and other indexing services in the very near future, and look forward to publishing many more papers in the coming year. You may not be aware that we also offer Open Access publication in Rhinology for a moderate fee and with priority handling.

Alongside all of these initiatives we feel that this year is the right time to increase the number of issues of Rhinology from 4 to 6 . This will enable us to continue to serve our authors and readers by earlier publication of more high quality rhinologic papers.
In this first issue of the year, we bring you 3 interesting reviews on very different subjects, from the clinical implications of fluid dynamics, to the advantages of fibrin tissue adhesive over packing, to the role of $\mathrm{IgE}$ in non-allergic rhinitis. In recent years non-allergic rhinitis has received a lot of interest: in particular the different phenotypes ${ }^{(1,2)}$, endotypes ${ }^{(3)}$, the impact on quality of life ${ }^{(4)}$ and the potential role of $\mathrm{IgE}$ in local allergic rhinitis $(\mathrm{LAR})^{(5-7)}$. The prevalence of LAR reported in the literature has been extremely variable (0-100\%); Hamizan's review in this issue explains many of these discrepancies. The overall prevalence of $\lg E$ in nasal secretion was found to be 10.2 (7.4-13.4) \%. However, where there is history of an identifiable aeroallergen which triggered nasal symptoms or seasonality of symptoms, the prevalence is 19.8 (14.5- 25.6) \%. On the other hand, patients who lacked a suggestive allergy history and had negative systemic allergy tests had zero probability of detectable nasal serum IgE (0 (0-3.1) \%). This useful review highlights history taking as a simple method to filter potential LAR patients from the general NAR population. This is important because LAR patients significantly differ from other phenotypes of NAR, not only in terms of symptoms ${ }^{(7)}$, but also the likelihood of developing asthma ${ }^{(8)}$ and susceptibility to treatment ${ }^{(9)}$.

This issue is packed with such interesting papers covering all aspects of Rhinology. I hope you will enjoy reading them.
1. Steelant B, Hox V, Van Gerven L, Dilissen E, Dekimpe E, Kasran A, et al. Nasal symptoms, epithelial injury and neurogenic inflammation in elite swimmers. Rhinology. 2018;56(3):279-87.

2. Surda P, Putala M, Siarnik P, Walker A, Bernic A, Fokkens W. Rhinitis and its impact on quality of life in swimmers. Allergy. 2018;73(5):1022-31.

3. Segboer $\mathrm{CL}$, Fokkens WJ, Terreehorst I, van Drunen CM. Endotyping of non-allergic, allergic and mixed rhinitis patients using a broad panel of biomarkers in nasal secretions. PloS one. 2018;13(7):e0200366.

4. Segboer $\mathrm{CL}$, Terreehorst I, Gevorgyan A, Hellings PW, van Drunen CM, Fokkens WJ. Quality of life is significantly impaired in nonallergic rhinitis patients. Allergy. 2018;73(5):1094-100.

5. Bozek A, Scierski W, Ignasiak B, Jarzab J, Misiolek M. The prevalence and characteristics of local allergic rhinitis in Poland

\section{Rhinology. 2018.}

6. Van Gerven L, Steelant B, Hellings PW. Nasal hyperreactivity in rhinitis: A diagnostic and therapeutic challenge. Allergy. 2018;73(9):1784-91

7. Hellings PW, Klimek L, Cingi C, Agache I, Akdis C, Bachert C, et al. Non-allergic rhinitis: Position paper of the European Academy of Allergy and Clinical Immunology. Allergy. 2017;72(11):1657-65.

8. Rondon C, Bogas G, Barrionuevo E, Blanca M, Torres MJ, Campo P. Nonallergic rhinitis and lower airway disease. Allergy. 2017;72(1):24-34.

9. Rondon C, Blanca-Lopez N, Campo P, Mayorga C, Jurado-Escobar R, Torres MJ, et al. Specific immunotherapy in local allergic rhinitis: A randomized, double-blind placebo-controlled trial with Phleum pratense subcutaneous allergen immunotherapy. Allergy. 2018;73(4):905-15.

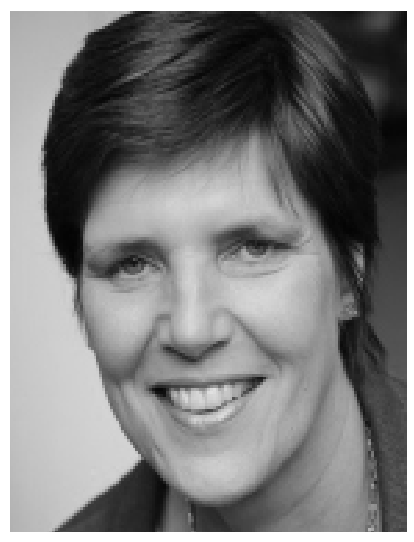

Wytske J. Fokkens, Editor-in Chief Amsterdam, the Netherlands 